\title{
Presenting a Succession Management Model Based on Organizational Capabilities in Knowledge-Based Organizations (Case Study: Science and Technology Park of Tehran University and Science and Technology Park of Tarbiat Modares University
}

Seyed Mehdi Alvani ${ }^{1}$

\author{
Rahmatollah Gholipour Souteh ${ }^{1}$
}

Gholam Reza Jandaghi ${ }^{1}$

Amin Balaghi Inaloo²

1-Professor and Faculty member, Faculty of Management, Farabi Campus, University of Tehran, Qom, Iran 2-PhD Scholar, Faculty of Management, University of Tehran, Tehran Iran

Doi:10.5901/mjss.2016.v7n2s2p199

\section{Abstract}

World in the present century is full of competition and uncertain environmental factors. The prerequisite of succeeding in this turbulent environment is to achieve numerous competitive advantages such as the ability of people and constant enhancement of quality and productivity level and this can be realized only with having much more intelligent, talented, capable and qualified individuals comparing to current managers who can direct organizations with their knowledge, expertise and experience and who can successfully deliver them to their destination. Succession planning management system with relying on organizational capabilities as a smart strategy for talent management can retain talents inside an organization and can assure the existence of the necessary and required skills for responding to quick environmental changes and can guarantee the future success of an organization. In the present study, with the title of "presenting a model for succession management based on organizational capabilities in knowledge-based organizations (case study: Science and Technology park of University of Tehran and Science and Technology park of Tarbiat Modares University" with the application of qualitative strategy of grounded theory, we have tried to study the current status of organizational capabilities and succession monument in Science and Technology park of University of Tehran and Science and Technology park of Tarbiat Modares University and to propose a comprehensive model for succession management based on organizational capabilities and proportional with the effective factors and internal and external characteristics of these two organizations. The approach used in this study is a mix approach and hence, for developing the comprehensive research model, qualitative and quantitative approaches (in combination with one another) were used. The present study in terms of methodology is a exploratory survey, causal, applied and fundamental study. Statistical population of the present study is consisted of academic experts and specialists in Science and Technology park of University of Tehran and Science and Technology Park of Tarbiat Modares University and data collection was continued until reaching a saturation point. For selecting sample volume, snow ball method was used and finally, the research model was developed based on the opinions of 27 experts. In the second stage, the presented research model was tested by using SPSS 20, Lisrel8.8 and smartPLS.03 and results indicated that the relationships and components of the proposed model are significant.

Keywords: Succession management, organizational capabilities, knowledge-based organizations, Science and Technology Park of University of Tehran, Technology Park of Tarbiat Modares University.

\section{Introduction}

Fast expansion of globalization has placed a lot of pressure on organization and so many managers have learnt that one of the characteristics of a successful organization is its ability in optimized identification, education and use of people (Barner, 2006). Such leaders can identify and recognize long-term strategic organizational goals (Romejko, 2008); hence, in some organizations succession planning programs are implemented for assuring the continuity of successful leadership; because senior managers of these organizations believe that succession planning guarantees the future success of their organizations (Mandi, 2008). On the other hand, succession planning enables an organization to identify its knowledge gaps and to foster and train its employees in a way to be able to express their desires about career development in a safe, positive and comfortable environment (Christie, 2005; Mateso, 2010).

It should be acknowledged that in today's dynamic and changing environment, humans are the most important 
organizational element in governing many companies and organizations with relying on individuals as the most important capital, encouraging them to understand, perceive and provide their new ideas and knowledge and to make use of these ideas in practice for achieving organizational goals. These activities require the organizational culture, as the factor shaping the character of organizations which influences the employees' behaviors, to be a culture which promotes and supports knowledge activities (Ndubisi, 2008). It is because, human resources is one of the most valuable and important assets of an organization (Bagley, 2008) and in fact, succession planning is more than just filling the empty organizational positions and is also a smart strategy of talent management which can help an organization to retain its talents and can assure it of having the necessary skills for responding to quick changes in today's business world (Hills, 2009). Succession planning enables an organization to identify its knowledge gaps and to foster and train its employees in a way that they can express their desires about their career development in a safe, positive and comfortable environment (Christie, 2005; Rothwell, 2010)..

It should be mentioned that today in knowledge based organizations, the most important competitive advantage in today's competitive world is human resources which determine the success or failure of organizations. On the other hand, lack of on-time replacement of expert and specialized individuals in organizational posts is one of the concerns that every organization is facing with. Therefore, a successful and prospective manager should identify human talents in his/her organization for filling its key posts in future and through various training programs should prepare these talents for intended future posts. Since, organizations in future are going to face increasing competitive challenges and for managing these challenges they would be needing more qualified and more effective mangers than their current mangers, hence, talents management or succession management will gain a greater importance every day in prospective organization (Najafi, 2006).

Also, one of the most fundamental and important challenges facing organizations, is the increased need to empowered managers and employees in future years. So many organizations that are prone to deterioration and destruction don't have any plan for satisfying their future needs to mangers and leave the things the way they are and take a passive approach in facing with issues like this. These organizations are considered as those who observe the future (Appelbaum et al., 2012). Another group of organizations for satisfying their future managerial needs absorb and make use of external talented managers and employees without considering their internal human resources. These organizations are known as those who choose the future and finally, a small number of smart organizations who are seeking to maintain and improve their position, rely their planning on identification and training of managerial talents from the human resources within their organization (at first) and outside of their organizations, eventually. These organizations are seeking to build the future (Bagley, 2008). Hence, they can be considered as future building or pioneer organizations. These organizations with understanding the importance and the extent to which mangers affect growth and success, seek to develop and implement serious and systematic talent identification and succession planning programs (Eidi and Diyanati, 2008).

Since the main function and goal of Science and Technology park is to aid the development of knowledge-based businesses and as a result, to increase the Scientific and economic power of Iran with relying on scientific power and considering the fact that Science and Technology park has the following important responsibilities which doubles the importance and sensitivity of human resources specially at managerial level (Sherman, 2009):

- Increasing Gross National Product through creating new products and markets;

- Creating jobs, especially for knowledge-based and educated manpower in Iran;

- Improving the position of knowledge-based activities and absorbing elites and avoiding brain drain;

- Commercialization of academic research results and findings;

- Creating a communicational chain between industries and universities and hence, facilitating and reducing the required time for using the findings of studies, specially for start-up companies and industries;

- Increasing the level of risk-taking and the competitive power of domestic IT companies and aiding their presence at international level.

It should be mentioned that achieving the goals of these two critical organizations depends on effective and optimized management of their human resources and taking measures for absorbing and distributing manpower, and to develop and retain their human resources can have a significant effect on increasing the quality of services in these two Science and Technology parks (Dimovski et al., 2008).

As it was mentioned, succession planning has a broad concept which encompasses so many areas. In this study, we seek to develop a model of succession management based on organizational dimensions in knowledge-based organizations in two Science and Technology parks of University of Tehran and Tarbiat Modares University. Several models have been proposed for succession planning, however, the important point is that the model for succession 
management in each organization is specific to only that organization. Considering the above arguments, it can be concluded that organizations should focus on their succession planning and management for achieving success and hence, the main research problem in the present study is that "what is the appropriate model for succession management based on organizational capabilities in knowledge-based organizations?" For this purpose, in the following sections research theoretical background, method, findings and conclusion are presented.

\section{Theoretical Background}

The term, succession planning is used for a broad spectrum of capital planning for future needs of employees. Wolfe (1996) has presented a Brilliant definition of succession planning. He defines it as a certain program which systemizes an organization for assuring leadership continuity for all its key posts through developmental activities which builds on employees' talents. Baldwin (2000) assumes that every key post inside an organization should be identified, which includes the identification of skills, knowledge and qualifications of current manpower and determining the required set of skills, knowledge and qualification for facing with the requirements of future manpower for achieving organizations goals, perspective and mission. Fenner (2005) , states that succession planning is to find that an organization have systematically identified and prepared candidates with high potential for key organization posts. Leadership theorists believe that succession planning requires the identification of those employees who have proper carrier development skills and training for facing with future leadership challenges.

Succession planning is more and beyond only filling empty positions in an organization and it is a smart strategy for talent management that can aid the retention of talents in an organization and can assure an organization of having the required skills for responding to quick changes caused by today's business environment (Hills, 2008).

Succession planning in addition to being complex requires a constant attention and continuous resources and should be considered as a continuous process. The fact that succession planning should be a top-bottom process, indicate that the most significant aid of an organization is to creating a long-term development for its employees (Watson, 2009). Sam Brooke (2005), considers succession planning as an effort toward planning for considering the appropriate number of managers with appropriate quality and also having skilled and key employees for covering and filling empty posts in organizations caused by retirement, death, The incidence of serious disease or promotion as well as any king of new posts and organizational positions which might be created in future plans of an organization (Anthony Perrrenoud, 2012). The main aim of a comprehensive succession plan should be to transfer the knowledge possessed by key organizational individuals before they leave the organization (Lowe, 2003).

A good succession planning management system should have the following important components:

- Strategic Statement;

- Database;

- An open and correct communication channel;

- Supportive mangers;

- Systematic attitude in identification of Potential successor candidates;

- Rewarding managers for promoting best employees;

- Participation, feedback and activity (Ndubisi, 2008).

About the importance of succession planning process in organizations, Lavinga says that succession planning is a fundamental and critical factor which should be related to strategic goals of an organization and should be derived from organizational strategy and should engage line managers directly. Nadler (2006) also believes that mangers' succession is the second importance issue that today's organizations are facing with (Lambertides, 2009).

So many of today's human capital changelings are rather new challenges. It is necessary to consider a very serious and new succession plan, because we are facing with nontraditional work methods such as remote exchanges, multigenerational manpower as well as lack of human talents today which weren't existing in past decades. This planning can be considered as a tool which satisfies future needs of an organization to employees. A planning that always has a number of successor candidates for critical positions in an organization in mind and focuses on the quality of these candidates in terms of their qualifications and skills. Succession planning provides an organization with leaders with strategies of knowledge transfer and sharing who compensate for the lack of knowledge due to retirement, promote and manpower exhaustion (Hilton and Jackson, 2007). Also, the urgent need to succession planning and its importance for marinating and continuing stability, reduction in costs, training leaders and driving economic growth in business sector are among the most important priorities (Ryan C. Sherman, 2009).

Based on the evolutionary approach toward growth process, succession theories can be classified surrounding 
three pillars of "replacement planning", "succession planning" and "succession planning management":

\subsection{Replacement planning}

Some executive managers believe that the first responsibility of any mangers is to determine a replacement for him/her. This traditional view emphasizes on the necessity of management continuity and the responsibility of the main managers in selecting his replacement.

\subsection{Succession planning}

Succession planning refers to a systematic process in which attention is paid to the requirements of managerial and key posts through a performance appraisal process, ratio of quality to quantity of top and middle level managers. This stage of evolution of succession has been raised for responding to shortcomings observed in simple replacement charts and with this items such as studying job requirements, dynamics of organizational changing needs, candidates information, information about performance, special tasks and decisions of candidates trainings and education attracted attention (Rothwell, 1998).

\subsection{Succession planning management (management succession)}

Today instead of succession planning, management succession is used which is focused in the managers' framework (Anthony Perrrenoud, 2012). In succession planning, planning is performed on all key posts, however, in this new approach to succession, planning is focused on managers' framework (Rothwell, 2005). In succession planning, planning only focuses on identification of executive managers, while, in management succession, estimated performance assessments in all levels are extensively referred to. Previously in succession planning the system was considered as confidential and secret, however, today, management succession relies on an open systematic process and eventually, it can be claimed that in management succession, a set of managerial talents reserves are fostered; while, in succession planning, individuals are merely identified for key positions and post. In Volum's view, management succession today is a combination and mix of the science and art of succession and career of management (Modise, 2011).

\section{Research Method}

The present study is an applied - fundamental research in terms of goal and in terms of data collection and analysis method is a combined study (qualitative and quantitative) and since, in this study the researcher seeks to presents a model of succession planning management based on organizational capabilities in knowledge-based organizations, in terms of research method it is an exploratory research and in terms of method of conduct it is a survey study that one of the most important advantage of it is the generalizability of obtained findings.

\subsection{Data collection methods}

In the present study, the most important method of data collection in developing the model is using interview and in testing the presented model is using questionnaire. In the meantime, the researcher in some cases has used other methods such as observation, studying documents and participation of the researcher as well. Since, the most important method used for data collection was interviews, in the following section this method is described briefly.

\subsection{Research population and sample}

Statistical population of the present study is consisted of two parts. The 1st parts is related to model development which is consisted of managers and experts in Science and Technology park of University of Tehran and Science and Technology park of Tarbiat Modares University as well as experts, professors and specialists of the field of this study. In the first part, research population is equal to research sample and is consisted of 27 individuals and by using snow ball method, Interviewees were asked to introduce informed individuals regarding the topic of this study for subsequent interviews. With performing these interviews, the researcher has decided that data collection has reached a saturation point and that there is no need to perform more interviews. The second part of statistical population is related to testing the proposed model and for this purpose, a number of 78 questionnaires were distributed among managers and experts 
of Science and Technology park of University of Tehran and Science and Technology park of Tarbiat Modares University that 71 questionnaires were returned and finally, 70 completed questionnaires were used as the basis for data analysis.

\subsection{Data analysis method}

In this study, for analyzing the data collected from interviews, the Three-step process of open, axial and selective coding was used. This process is started in a way that the researcher first starts with reviewing and reading the data collected from interviews regarding succession planning management system and then coding similar data with similar semantics and next, allocates proportional concepts to each of them. During this step which is known as open coding, various and multiple categories related to succession planning management system were extracted. Each of these categories are based on different concepts and researcher has tried to develop a number of dimensions and characteristics for each concept for a better understanding and identification of the fluctuations of that concept. When, the categories were forced, researcher has selected a category that its trace is evident in various sections of data. This category which is known as the axial category, was extracted under axial data coding and the origin and root of all the topics related to succession planning management based on organizational capabilities in knowledge-based organizations can be found in it. In the next step, the researcher has tried to understand the relationship of each of the other categories to the axial category. In this step, the position of other categories are specified with relation to the axial category; that is, the researcher among the other categories, has tried to identify causal conditions, intervening condition, contextual conditions of strategies and outcomes. Next, the intervention manner of each of these categories in the occurrence of the axial category has been described in a narrative manner. In the last step, through reviewing, refining and completing the categories and concepts extracted from data, the theory related to succession planning management system has been developed. In this stage which is known as selective coding, the occurrence flow of the succession planning management system has been described by using the existing or new categories and concepts. This step has led to the proposal of model for succession planning management system of knowledge-based organizations.

The next step after proposing the research model which is the output of the qualitative section of the research and is the result of interviews and Grounded Theory, is the quantities part of the research or model testing (theory testing) by using structural equation modeling. It should be mentioned that in this section, first a questionnaire was developed based on indexes, dimensions, concepts and categories of the proposed model which is consisted of 75 items. The developed questionnaire uses a five-point Likert's scale with options of very low (score 1), low (score 2), average (score 3), high (score 4) and finally, very high (score 5).

After testing and confirming the questionnaire in terms of its validity (the questionnaire was distributed among experts, specialists and advisor and supervisor professors and they were asked to provide their opinions about each item, the validity of the questionnaire was confirmed by them with minor modifications) and its reliability (a pilot test was conducted on the questionnaire by distributing it among a few number of the research population and it was collected back and data were entered in SPSS software and its Cronbach's alpha was calculated which was larger than 70\% (82\%) and hence, it can be claimed that research questionnaire has the necessary reliability), the questionnaire was distributed among the research population. From the 78 distributed questionnaires, 71 questionnaire were returned back and finally 70 completed questionnaires were used for data analysis. The average questionnaire return rate in this study is equal to $89 \%$, which is a satisfactory rate considering the culture of research in our country. After collecting data, for testing the proposed research model, Confirmatory factor analysis and structural equation modeling methods in LISREL 8.80 and smartpls. 03 were used.

\section{Data Analysis and Research Findings}

Descriptive statistics of each of the 6 components of grounded theory are presented in table 1 . The variable of causal conditions has an average and standard deviation of 3.11 and 0.59 , respectively. Average and standard deviation of the axial category are equal to 3.20 and 0.67 , respectively; for strategies these values are equal to 3.56 and 0.43 , respectively; for contextual conditions these values are equal to 3.24 and 0.68 , respectively; for intervening conditions they are equal to 3.41 and 0.44 and for outcomes they are equal to 3.16 and 0.74 , respectively. 
Table 1 - General statistics of research variables

\begin{tabular}{|l|c|c|c|c|c|}
\hline \multirow{2}{*}{ Variable } & \multicolumn{5}{|c|}{ Statistics } \\
\cline { 2 - 6 } & Average & Standard deviation & Variance & Min. & Max. \\
\hline Causal conditions & 3.11 & 0.59 & 0.35 & 1.90 & 4.28 \\
\hline Axial category & 3.20 & 0.67 & 0.45 & 1.50 & 4.50 \\
\hline Strategies & 3.56 & 0.43 & 0.18 & 2.75 & 4.63 \\
\hline Contextual conditions & 3.24 & 0.68 & 0.46 & 1.77 & 4.62 \\
\hline Intervening conditions & 3.41 & 0.44 & 0.20 & 2.62 & 4.46 \\
\hline Outcomes & 3.16 & 0.74 & 0.55 & 1.64 & 4.91 \\
\hline
\end{tabular}

Next, data collected from interviews were carefully studied and analyzed. To similar data, proportionally similar concepts were allocated. For example, b studying the following direct quote, the researcher has found the two concepts of "inclination toward service continuity" and "effective application and retention of human resources".

"The necessity of fostering successor is to retain employees which means to prevent them from leaving organization and to maintain and retain individual in their various organizational post which in turn requires the management to increase the positive attitude of employees toward service continuity of employees by using Effective payment system, education and development, granting amenities and appropriate services and ... . In general, retaining employees means that the job conditions for individuals should be good so that they will not leave their organization and join another organization due to undesirable job conditions. "

In the above quote, researcher has extracted the concept of "inclination toward service continuity" from the respondent's hints about positive attitude about service continuity of employees. However, this hint exists in other quotes as well and researcher in the process of data comparison has extracted this label. Also, in the above quote, the respondent has referred to retaining which is equal to the concept of preventing turnover and retaining individuals in their different organizational posts and positions. Considering these phrases, researchers have extracted the label of "effective application and retaining human resources". Other concepts were extracted in the same manner.

After studying data, labeling events and extracting concepts, each of these concepts were compared with one another, in order to determine their similarities and differences. This has been performed for forming categories. For example, for comparing different concepts, researchers has noticed that the concepts of "inclination toward service continuity" and "effective application and retaining human resources" in fact, refers to one thing; which is equal to "retention system of human resources".

Considering to this, researcher from these two concepts has extracted the category of retention system. This concept has a higher level comparing to the above concepts, is more abstract and covered both the above concepts. Other categories also were extracted in the same manner. Totally, 20 categories and 75 concepts were identified. In the next step, axial coding was performed in which among the extracted categories, the category of succession planning was considered as the axial category and is placed at the center of research model and then, other categories are placed under another 5 groups including causal conditions (events that lead to the occurrence of the indented phenomenon), context (a set of special characteristics which indicate to the indented phenomenon); intervening conditions (structural condition which belong to the intended phenomenon and are effective on action and reaction strategies); strategies (action and reaction which are caused for governing, controlling or responding to an axial category); strategies (results and Outcomes of action and reaction) and outcomes. Therefore, axial coding mole is as per figure (1). 


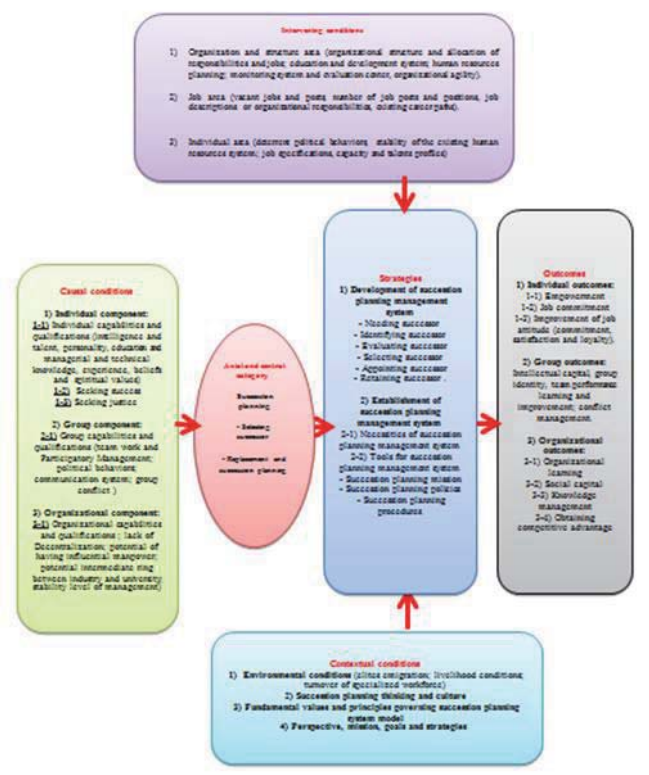

Figure (1) Axial coding model: development of succession planning management based on organizational capabilities in knowledge-based organizations.

Final step is selective coding in which theories are proposed based on the results of open and axial coding. This step is the integration, improvement and refinement process of categories. For this purpose, with creating a certain rhythm and layout among categories, they are set for presenting and shaping a theory. At this level, it has been tried to present a theoretical narrative for the phenomenon with putting together the categories around the axial category as the central and main category and also, to create a systematic relationship around this main string between concepts and categories. Results of data analysis indicated that establishing a professional and appropriate system can accurately, correctly and reliably evaluate, measure and determine the level of succession planning management. Results of selective coding has led to extraction of the following model. Results obtained from this step can be presented in the form of the following model:

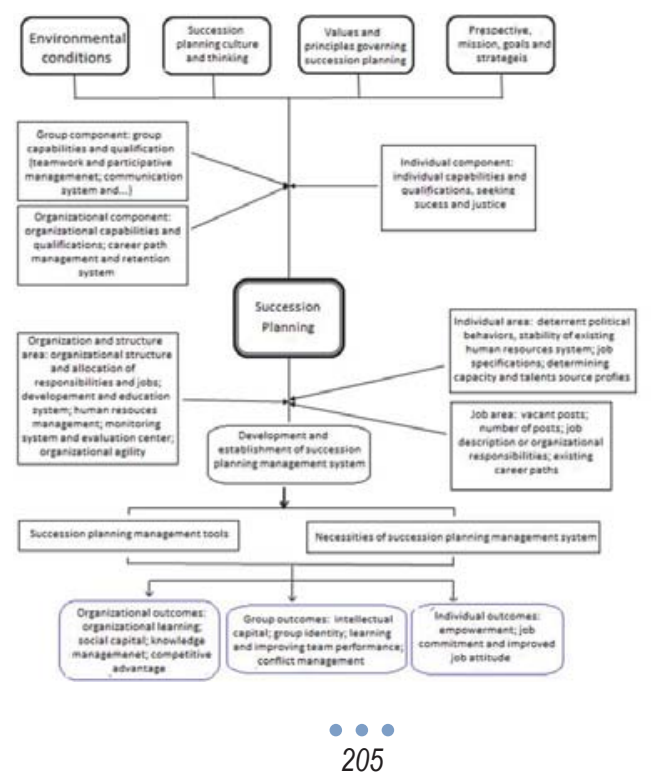


1st step in testing the proposed model is to develop, distribute and collect questionnaire and after collecting data, performing Confirmatory factor analysis on each of the questionnaire constructions (causal conditions, axial category, strategies, outcomes, intervening conditions, context) by LISREL8.80 indicated that all the considered indexes for all the items related to model variables have a factor loading (correlation) larger than 0.3 which indicate that factor loadings are rather large and desirable. On the other hand, all significance values of the model's parameters are larger than 1.96. Hence, in general, with considering the level of factor loadings and their significance together with desirable goodness of fit of the model we can determine the validity and reliability of the measuring mode. After testing and evaluating the used items and questions in the questions in terms of goodness of fit of the measuring model, researcher has tested the existing structural equation test in research model by using structural equation modeling in SmartPLS (due to small sample volume, using second order variable and also existence of moderating relationships in the model), the results of which are presented in figures (1) and (2) which indicated that the research model is good and is confirmed.

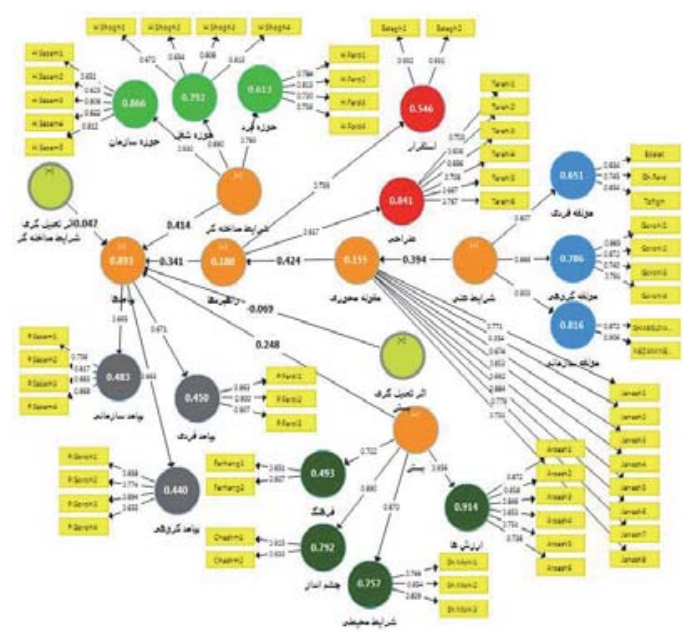

Figure 1 - Structural model in the case of standard estimation

In figure (2) also, the model of significance values related to it are presented.

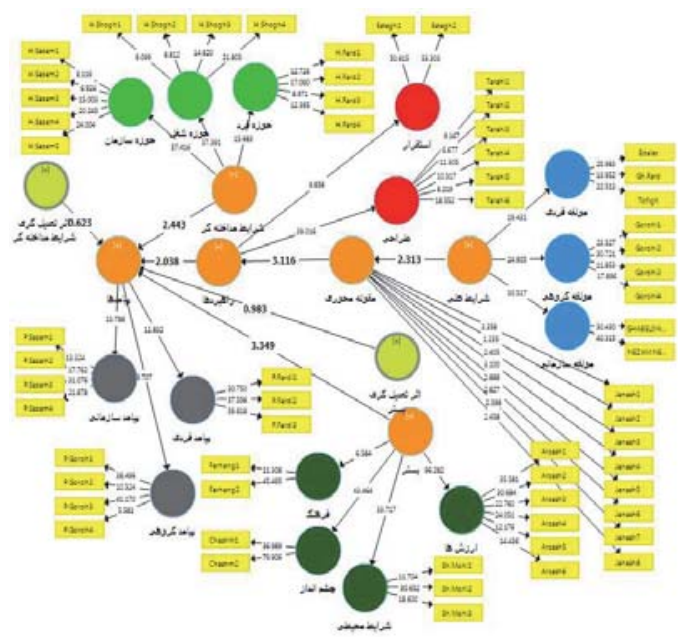

Figure 2 - Structural model in the case of significance coefficients 


\section{Conclusion}

Considering the fact that researcher in the present study sought to propose a model of succession planning management based on organizational capabilities in knowledge - based organizations in Science and Technology park of University of Tehran and Science and Technology park of Tarbiat Modares University, hence, by using qualitative strategy of grounded theory the current status of organizational capabilities and succession planning management in Science and Technology park of University of Tehran and Science and Technology park of Tarbiat Modares University was analyzed. It should be noted that the used approach in the present study, is a mix approach and for developing a comprehensive model of succession planning management qualitative and quantitative approaches (in combination with one another) were used. Statistical population of the present study is consisted of academic experts and specialists in Science and Technology park of University of Tehran and Science and Technology park of Tarbiat Modares University and data collection was continued until reaching a saturation point; also, for selecting sample volume snow ball method was used and finally, the propose model was developed based on the opinions of 27 experts. Results obtained from analyzing interviews indicated that among the extracted categories, the category of succession planning is considered as the axial and central category of the model. Also, among the other categories, 7 categories of "personal capabilities and qualifications", "seeking success", "seeking justice", "group capabilities and qualifications", "organizational capabilities and qualifications", "career development management" and "retention system" were considered as casual conditions. That is, they are among the causes of succession planning management system in an organization. Categories of organizational and structure areas (organizational structure and allocation of responsibilities and tasks; educational and development system; human resources planning; monitoring System and evaluation center, organizational agility); career area (vacant jobs and posts; number of posts; job description; existing job paths) and individual area (preventing political behaviors; stability of the existing human resources system; job specifications; determining capacity and talents profiles) are considered as intervening conditions, because these categories can facilitate or prevent the achievement of axial category. Categories of environmental conditions; the culture and thinking of succession planning; fundamental values and principles governing succession planning system model; perspective, mission, goals and strategies; development of succession planning management system (needing a successor; identifying a successor; evaluating a successor; selecting a successor; appointing a successor; retaining a successor) were considered as contextual conditions. Categories of establishment of succession planning management system, necessity of a succession planning management system; succession planning management system tools were also considered as strategies and finally, the categories of individual outcomes such as job empowerment and commitment; group outcomes such as intellectual capital and group identity and organizational outcomes such as organizational learning and obtaining competitive advantage were considered as outcomes of developing and establishing succession planning management model based on organizational capabilities. In the second step, the proposed model was tested by using SPSS 20, Lisrel8.8 and SmartPLS.03 and results indicated that the research model's relationships and components are significant.

\section{References}

Anthony Perrenoud, (2005), Effective Succession Planning in Construction Companies, A Thesis Presented in Partial Fulfillment of the Requirements for the Degree Master of Science, Arizona State University.

Appelbaum, E., Bailey, T., Berg, P., \& Kalleberg, A., (2012), Manufacturing advantage: Why high-performance work systems pay off. Ithaca, NY: ILR Press.

Bagley, T. L., (2008). Employee retention and succession planning for a Department of the Navy program office.

Baldwin, D. (2000). The strategy of succession planning. Retrieved August 4, from http://www.businessknowhow.com/manage,susses plan.htm.

Barner, R., (2006), Bench Strength. San Francisco. American Management Association.

Christie, Sue. , (2005), "Succession planning: there are no magic bullets". Policy \& Practice of Public Human Services.

Dimovski, V., Skerlavaj, M., Kimman, M., Hernaus, T. (2008) Comparative Analysis of the Organizational Learning Process in Slovenia, Croatia, and Malaysia. Expert Systems with Applications, 34(4),pp: 3063-3070.

Eidi, A. and Diyanati, M. , (2008), Assessment centers, new method of succession Planning,Tadbir, No 195, pp: 18-29.

Fenner E., (2005), "Establishing talent management for company's succession planning through analytic network process: Application to an MNC semiconductor company in Taiwan", Public Personnel Management (2004) 33.4, pp: 357- 361.

Helton, K. A., \& Jackson, R. D., (2007), Navagation Pennsylvania's Dynamic Workforce: Succession Planning in a Complex Environment. Public Personnel Management, 335-347.

Hills, Angela. , ( 2009), INDUSTRIAL AND COMMERCIAL TRAINING эVOL. 41 NO. 1, pp. 3-8, Q Emerald Group Publishing Limited, ISSN 0019-7858 j.

Lambertides, N. , (2009), Sudden CEO vacancy and the long-run economic consequences. Managerial Finance, Vol. 35 No. 7, pp. 645- 
661.

Lavinga, A. , (2010), Next Generation Talent Management: Talent Management to Survive Turmoil, Law Library Journal, Vol. 98 No. 2, pp. 433-8.

Lowe, R. K. , (2003), Animation and learning: selective processing of information in dynamic graphics. Learning and Instruction, 13, 247262.

Mandi, A.R.,(2008), A Case Study Exploring Succession Planning: Supported by Quantitative Analysis of Governmental Organizations in the Kingdom of Bahrain. Dissertation Submitted to The George Washington University.

Mateso, Peter.E.E, (2010), Understanding Succession Planning and Management Efforts at Midwestern University: A Mixed Methods Study, Submitted to the Graduate College of BowlingGreen State University in partial fulfillment of the requirements of the degree of Doctor Of Education, pp:1- 270.

Modise M. (2011). Macroeconomic Variables and South African Stock Return Predictability. Working paper.

Nadler P. A., (2006),"The role of flexible job descriptions in succession management", Journal of Social Behavior and Personality, 14(4),pp: 503-521.

Najafi A.,(2006), Succession planning and talent Management, Master's Thesis, Islamic Azad University, Science and Research.

Ndubisi N (2008). Impact of Personal Culture on Sophisticated Succession Planning by SMEs on Malaysia. Proceedings of the Allied Academies. 15(2):187.

Romejko, M.A.,(2008), Key Characteristics of a Succession Planning Program at a Government research Center, Dissertation Submitted to Pepperdine University.

Rothwell William J.,(2005) "Effective Succession Planning", American Management Association.

Rothwell, W. J.,(1998),"Effective succession planning: ensuring leadership continuity and building talent from within (3rd ed.)”. New York: Amacom.

Sambrook, S.,(2005). Exploring succession planning in small, growing firms. Journal of Business and Enterprise Development, 12(4), 579-594.

Sherman, Ryan C.,(2009), Succession Planning: A study of superintendent succession within the school districts of the WarrenSaratoga-Washington-Hamilton-Essex County Board of Cooperative Educational Services A Doctoral Research Project Presented to Associate Professor Dr. Ann Myers Doctoral Research Committee Chair School of Education The Sage Colleges, pp:1-91.

Watson, C. , (2009), Succession planning: Developing leaders for the future of the organization. Leadership Abstracts, Policy \& Practice of Public Human Services.

Wolfe, Rebecca Luhn. (1996),Systematic Succession Planning: Building Leadership from Withim. Boston, MA: Course Technology. 